\title{
VJEŽBE PREVOĐENJA ZA NEIZVORNE GOVORNIKE HRVATSKOGA JEZIKA
}

\author{
Ninoslav Radaković \\ Fakultet za poljsku i klasičnu filologiju Sveučilišta Adama Mickiewicza u Poznanju
}

\begin{abstract}
Učlanku su iznesene neke teorijske postavke prevođenja i metodike nastave prevođenja. Opisana je Prevoditeljska radionica provođenja na Sveučilištu Adama Mickiewicza u Poznanju (Poljska). Cilj je radionice upoznati studente s teorijom prevođenja i svim funkcionalnim stilovima hrvatskoga jezika te prevesti što više različitih tekstova s hrvatskoga na poljski i obratno u svrhu stjecanja prevoditeljskoga iskustva i s njim povezanoga samopouzdanja. Silabus navedenoga predmeta uključuje početno upoznavanje s teorijom prevođenja i uspoređivanje već prevedenih tekstova hrvatskih autora na poljski (i obratno) s njihovim izvornikom. Studenti počinju prevoditi kratke i jednostavne novinske članke na hrvatskom, a nakon toga slične tekstove prevode s materinskoga jezika na hrvatski. Prema načelu postupnosti u korpus prevođenih tekstova polako se uključuju i kompliciraniji tekstovi: književnoumjetnička proza, enciklopedijske natuknice i znanstveni članci, različiti obrasci i dokumenti, koji uključuju razne zakone, propise i javnobilježničke potvrde. Posljednja i ujedno najzahtjevnija faza odnosi se na prijevod poezije.
\end{abstract}

Ključne riječi: komunikacijska kompetencija, međukulturna kompetencija,
prevoditeljske kompetencije, prevođenje

\section{UVOD}

Prevođenje je proces u kojem poruku izrečenu na jednom jeziku pretvaramo, prenosimo $u$ jednakovrijednu poruku izrečenu drugim jezikom. Pritom ne smijemo zaboraviti da prevođenje nije isključivo zamjena riječi ili jezičnih struktura jednoga jezika riječima ili strukturama drugoga jezika; $u$ tom složenom komunikacijskom procesu prevoditelj se nalazi u dvostrukoj ulozi (primatelja izvorne poruke pošiljatelja te pošiljatelja prevedene poruke krajnjem primatelju) i mora voditi računa o čitatelju teksta prevedenog $\mathrm{u}$ konkretnoj situaciji, konkretnoj kulturi i za konkretne potrebe. To ujedno znači da se prevođenje temelji na prenošenju teksta najbližim prirodnim ekvivalentima, ponajprije na razini značenja, a zatim stilski (usp. Ivir, 1978: 9-11; Nida, 1981: 331; Pisarska i Tomaszkiewicz, 1996: 7). Stoga mnogi proučavatelji i teoretičari prijevoda i prevođenja govore da je prevođenje više kulturni nego jezični problem, odnosno da prevođenje služi upravo komunikaciji među različitim kulturama, premošćivanju kulturnih razlika

ninoslav.radakovic@gmail.com 
i rušenju kulturnih barijera (usp. Fernández Guerra, 2012: 1; Ivir, 1978: 63; Ivir, 2002: 117; Modrzejewska, 2000: 30; Tokarz, 2008: 8; Wilczek, 2008: 26).

Kultura se najčešće definira kao „složena cjelina institucija, vrijednosti, predodžaba i praksi koje čine život određene ljudske skupine, a prenose se i primaju učenjem “1, odnosno "ukupnost materijalnih i duhovnih dobara, etičkih i društvenih vrijednosti, što ih je stvorilo čovječanstvo “2. Tako shvaćena kultura odnosi se na znanje, vjeru, umjetnost, moral, zakone i običaje, pa prevođenje kao čin međukulturne komunikacije podrazumijeva dobro poznavanje razlika u sustavu vrijednosti, shvaćanju svijeta, društvenim, političkim i pravnim kategorijama, običajima, očekivanjima, normama i konvencijama u ponašanju (usp. enciklopedija.hr, Modrzejewska, 2000: 30). Budući da kulturu, kao društveno stečeno znanje, stječemo učenjem jezika, i stranu kulturu možemo spoznati posredstvom stranog jezika (Novosel, 2012: 11).

\section{TEORIJA}

Zbog sve veće uloge prevoditelja u suvremenom društvu razlikuje se sve više pogleda na prevoditeljske kompetencije, a pri njihovu određivanju i procjeni polazi se od ocjene (teksta) prijevoda i njegove usporedbe s izvornikom. Općenito se smatra da je prevoditelj dužan prenijeti cijeli sadržaj originalnog teksta, prijevod se mora odlikovati slobodom, prirodnošću i lakoćom izvornika, a njegova forma i poetičnost moraju imati isti karakter kao polazni tekst (Pieńkos, 2003: 387; Piotrowska, 2007: 116).

Kompetencije ranije često izdvajane kao primarne: jezična kompetencija - u najširem značenju uključuje poznavanje gramatičkih struktura, leksika i stila obaju jezika; komunikacijska - shvaćena kao sposobnost pamćenja i vjernog prenošenja poruke uz poznavanje realija obaju jezika i kultura te prijevodna - vladanje prevoditeljskim tehnikama i strategijama (usp. Ivir, 1978: 16; Janikowski, 2012: 32; Piotrowska, 2007: 117; Zaręba, 2000: 17-18), smatraju se nedovoljnima i dobivaju sve konkretnija određenja i nazive kao što su: tekstualna kompetencija (razumijevanje i reverbalizacija), enciklopedijska, logička, retoričko-pragmatička, bilingvalna, stečena međujezična kompetencija, disimilacijska, istraživačka, transferna, kulturna, kompetencija produkcije teksta, kompetencija procjene vrijednosti prijevoda, neraskidiva veza praktičnog i teorijskog znanja, poznavanje kultura obaju jezika prijevoda, opće i specifično znanje, sposobnost indukcije, diskursna i strategijska kompetencija itd. Osim općih kompetencija izdvajaju se i posebne, ovisno o vrsti prijevoda kojom se prevoditelj bavi, a nije rijetkost ni da se $u$ kontekstu prevoditeljskih kompetencija govori o snalažljivosti

\footnotetext{
1 enciklopedija.hr

${ }^{2}$ hjp.znanje.hr
} 
na tržištu rada, ali i mnogim drugim poželjnim osobinama prevoditelja: kreativnost, marljivost, izdržljivost, dobro podnošenje umora i stresa, sposobnost logičkog razmišljanja i jasnog formuliranja misli, profesionalna skromnost, samokritika, odgovornost, etičnost... (usp. Janikowski, 2012: 37; Pieńkos, 2003: 385-389; Piotrowska 2007: 118-130, Pisarska i Tomaszkiewicz, 1996: 68-70; Zaręba 2000: 26).

Razvijanje i usavršavanje prevoditeljskih kompetencija, dakle, važan su metodički problem. Često smatrane kao nadgradnja i proširenje svih općih (deklarativno znanje, vještine i umijeća, „egzistencijalne“ kompetencije, sposobnost učenja) i komunikacijskih jezičnih kompetencija prosječnog korisnika jezika, usavršavane su poticanjem njihova razvijanja (usp. Gulešić Machata i Grgić, 2015; Piotrowska, 2007: 118; ZEROJ, 2005). U skladu s tim stavom predlaže se održavanje vježbi temeljenih na studentskom odigravanju situacija koje bi se mogle dogoditi u raznim kulturama te preporučuje korištenje povijesnih, političkih, pravnih, religioznih i književnih tekstova. Kako bi budući prevoditelj upoznao prosječnog korisnika stranog jezika i kulturu njegove zemlje, a ujedno osvijestio informacije o rodnom jeziku i kulturi, savjetuje se trostruka analiza (sociološka, antropološka i semiološka) svake teme iz opsega civilizacije (npr. sport, mladež, škola, posao, obitelj, slobodno vrijeme) (Modrzejewska, 2000: 30).

Sociološka analiza usmjerena je na skupinu i omogućuje smještanje pojave u društveni kontekst; daje osnovne statističke, ekonomske i političke podatke te pokazuje omjer analizirane pojave $\mathrm{u}$ odnosu na druge pojave $\mathrm{u}$ društvu, tj. zemlji jezika s kojeg se prevodi. Osnovni su materijali različiti izvještaji, studije, ankete različitih institucija, a dopuna može biti pripremanje sličnih materijala o istoj pojavi u zemlji na čiji se jezik prevodi. Antropološka analiza usmjerena je na pojedinca, konkretno djelovanje i ponašanje te omogućuje pogled na civilizaciju kroz prizmu stvarnosti svakodnevnog života, običaja, stavova. Materijali će sadržavati antropološke dokumente, novinske članke, komentare stručnjaka i sl. Potpunije razumijevanje pojave omogućuje semiološka analiza, usmjerena na kulturne konotacije, skupne predodžbe, mitove, priče, vjerovanja, povijesne ličnosti, znakove koje svi prepoznaju. Tako detaljnim uspoređivanjem obiju kultura upoznaju se njihove sličnosti i razlike (Modrzejewska, 2000: 31).

U suvremenoj metodici nastave prevođenja za održavanje vježbi prevođenja preporučuju se tri vrste zadataka: pripremne vježbe (usporedna analiza tekstova na oba jezika, rječnička analiza, problemska analiza, vježbe parafraziranja, čitanje izvornih i pomoćnih materijala, ispravljanje tekstova na ciljnom jeziku, određivanje prevoditeljskih tehnika i strategija, terminološke vježbe, pomoćne jezične vježbe), prevoditeljski zadatci (kontrastiranje doslovnog i idiomatskog prijevoda, raspravljanje o različitim varijantama prijevoda, uređivanje teksta, retranslacija /ponovno prevođenje na izvorni 
jezik ranije prevedenih tekstova/, hibridne vježbe /prevođenje fragmenata tekstova i njihovo uvrštavanje na odgovarajuće mjesto $u$ tekstu na jezikucilju/, grupno prevođenje, pojedinačno prevođenje uz grupno komentiranje) i prevoditeljski projekt (prevoditeljske radionice i susreti, timski prijevodi teksta na zahtjev). (usp. Kozłowska, 2000: 67; Piotrowska, 2007: 150-151).

\section{PRAKSA}

Iako je u mnogim zemljama i međunarodnim institucijama prisutna praksa prevođenja i obrazovanja prevoditelja isključivo na materinski jezik, zbog sve veće potrebe za prevoditeljima, na poljskim sveučilištima održavaju se vježbe prevođenja i na strani jezik. Istraživanje provedeno na Varšavskom sveučilištu (Kozlowska, 2000) pokazalo je da se i voditelji različitih prevoditeljskih kolegija i studenti slažu u ocjeni da je prevođenje na strani jezik teže od prevođenja na materinski. Razloge za to najčešće vide $\mathrm{u}$ razlikama u poznavanju dvaju jezika, njihovih realija i kulturnih krugova. Navode da je parafraziranje i izražavanje općenito jednostavnije na materinskom jeziku, na kojem su ujedno dostupniji analogni tekstovi i lakša je identifikacija s primateljem teksta, dok je manja potreba za konzultacijama i verifikacijom teksta prijevoda s izvornim govornikom.

Razlike $u$ prevođenju na materinski i strani jezik ukratko se mogu predstaviti na sljedeći način: pri prevođenju na strani jezik potrebno je savršeno aktivno znanje stranog jezika, dok je pri prevođenju na materinski jezik dovoljno pasivno poznavanje stranog jezika, tijekom prevođenja na strani jezik više problema izaziva sinteza, stvaranje teksta prijevoda, a tijekom prevođenja na materinski - analiza teksta originala. Za obje vrste prijevoda neophodno je poznavanje jezičnih realija (usp. Kozłowska, 2000: 67-68, Piotrowska, 2007: 135).

Bez obzira na to u kojem se smjeru prevodi (na materinski ili strani jezik), iste su faze procesa prijevoda: analiza ili (potpuno) razumijevanje teksta originala (i svih namjera i poruka autora), deverbalizacija (zadržavanje smisla teksta u pamćenju, ali oslobađanje od njegove jezične forme), sinteza ili reekspresija teksta (na jeziku-cilju) te verifikacija (usp. Kozłowska, 2000: 69; Pisarska i Tomaszkiewicz, 1996).

Silabus kolegija Prevoditeljska radionica (Warsztat tłumacza) uključuje početno upoznavanje studenata s (dijelom ovdje iznesenom) teorijom i tehnikom prevođenja. Pripremne vježbe uključuju usporednu analizu već prevedenih tekstova hrvatskih autora na poljski (i obratno) s njihovim izvornikom. Na taj način studenti vrlo brzo upoznaju najčešće zamke i pogreške u prevođenju (frazemi, lažni prijatelji i sl.), ali i načine njihova izbjegavanja. Vrlo je korisno uspoređivanje različitih prijevoda istih djela i raspravljanje o različitim varijantama prijevoda. Usporednom analizom studenti vrlo brzo upoznaju osnovne prevoditeljske strategije i tehnike 
(posuđivanje, definiranje, doslovno prevođenje, supstitucija, stvaranje nove riječi, kalkiranje, ekspanzija, redukcija, adaptacija, kompenzacija, generalizacija, komentiranje, modulacija, partikularizacija, transpozicija, varijacija, antonimija) (usp. Fernández Guerra, 2012: 7-12; Ivir, 2002: 118; Kozłowska, 2000: 63).

Prvi tekstovi koje studenti samostalno prevode obično su kratki i jednostavninovinski člancina hrvatskom, a nakon toga slične tekstoveprevode s poljskoga na hrvatski. Prema načelu postupnosti u korpus prevođenih tekstova polako se uključuju i kompliciraniji tekstovi: književnoumjetnička proza, enciklopedijske natuknice i znanstveni članci, različiti obrasci i dokumenti, koji uključuju razne zakone, propise i javnobilježničke potvrde. Posljednja i ujedno najzahtjevnija faza odnosi se na prijevod poezije. Pri prevođenju svih vrsta tekstova prolazi se sličan proces koji uključuje prvotno uspoređivanje sličnih tekstova na oba jezika, prevođenje s hrvatskog na poljski, a potom s poljskog na hrvatski. Na vježbama se kombinira grupno i individualno prevođenje uz obavezno komentiranje svakog prijevoda.

Poljski studenti hrvatske filologije uglavnom nemaju problema s prevođenjem elemenata kulture izrijekom navedenih $\mathrm{u}$ tekstu. Prijevodna radionica održava se na višim godinama studija, nakon što su u velikom stupnju usvojili hrvatski jezik.

Pri prevođenju s hrvatskog na poljski susreću se već poznati problemi $\mathrm{u}$ situacijama $\mathrm{u}$ kojima ne postoji odgovarajući ekvivalent na poljskom (npr. glagol uživati, koji se, ovisno o kontekstu, prevodi glagolima podobać się, bawić się, rozkoszować się, cieszyć się, prilogom przyjemnie ili imenicom przyjemność), kada isti leksemi imaju različito značenje (npr. apsolvent / absolwent/ u poljskom jeziku je osoba koja je završila školu, fakultet ili tečaj) ili u slučaju frazema istog sadržaja, a različitog značenja (npr. puknuo mu je film - urwał mu się film; poljska varijanta znači da se osoba o kojoj je riječ toliko napila da se ne sjeća svih događaja od tog dana). Dodatno, studenti često znaju „prepisivati“ glagolske prefikse i ne obraćati pozornost na različito značenje (ili nepostojanje) nekih prefikasa u hrvatskom i poljskom (npr. naplatiti - *napłacić - glagol ne postoji u suvremenom poljskom jeziku).

Pri prevođenju s poljskog na hrvatski studenti uglavnom čine gramatičke i pravopisne pogreške na koje nisu imuni ni pri uobičajenom korištenju hrvatskog jezika, često temeljene na prijenosu iz J1 u J2. Riječ je ponajčešće o zadržavanju genitiva uz negativnu konstrukciju i u hrvatskom tekstu (npr. Nije izgradio katedrale. umjesto Nije izgradio katedralu.), pogrešnoj glagolskoj rekciji (npr. *koristi s toga umjesto koristi se time), rjeđe o upotrebi pogrešnoga glagolskog oblika (npr. Kolektivni identitet utjecuje na individualni.) i korištenju "poljskog“ roda u imenica određenog tipa (npr. Nedostatak vitamine C.). Redoslijed (ne samo nenaglašenih) riječi u rečenicama prijevoda na hrvatski često je neobičan (npr. Važno je navesti da specifičan primjer kulturne politike je 
povijesna politika.), kao i upotreba poljskih pravila o pisanju velikog i malog početnog slova (npr. Filozofski Fakultet), što je osobito vidljivo u obraćanju (npr. Poštovana Gospodo!).

Najveći su prijevodni problem ponovno jezične strukture bez odgovarajućeg ekvivalenta u hrvatskom - od brojnih participa (npr. osoba mówiaca, što se obično prevodi kao govornik ili osoba koja govori) do frazema s nepostojećim ekvivalentom u hrvatskom (npr. o papieskiej/godzinie/-u vrijeme smrti pape Ivana Pavla II.) te korištenje neodgovarajućeg sinonima (npr. */s/ lomiti zakon umjesto /pre/kršiti zakon), rjeđe neodgovarajućeg prijedloga (npr. * prijeći kroz most).

Neku vrstu poteškoća pri prevođenju čine i elementi kulture koji nisu izrijekom navedeni u tekstu. Poljski govornik hrvatskog jezika neće na prvi pogled prepoznati aluzije na Domovinski rat ili suvremenu političku situaciju, kao ni o čemu je riječ u brojnim dječjim pjesmama i brojalicama. U takvim situacijama osobito je nužna lektorova pomoć u cjelovitom shvaćanju svih poruka i namjera (autora) teksta.

Jedan od takvih primjera je i sljedeća dječja pjesma:

Točka, točka, točkica...

Gotova je glavica.

Male uši, tanak vrat,

Trbuh mu je kao sat.

Male ručice, male nožice...

Eto našeg Jožice! (Maljković, 2014.)

Sudionici Prevoditeljske radionice ovako su ju preveli na poljski:

Kropka, kropka, kropeczka,

Gotowa jest główeczka.

Mate uszy, krótka szyjka

Jego brzuszek jest jak piłka.

Małe raczki, krótkie nóżki...

Oto jest nasz Jaś Kraglutki!

Izvorno napisanu na poljskom jeziku pjesmu sličnog tipa i namjene:

Kótko, kółko i kreseczka,

Tu laseczka, tam laseczka.

Widzi młody, widzi stary,

Że nam wyszły - okulary! (Skorek, 2006)

preveli su na hrvatski:

Kružić, kružić i crtica

I dva mala štapića.

Vide oči velike i male:

Dobili smo - naočale! 


\section{ZAKLJUČAK}

Nažalost, često se događa da za sve potrebne i poželjne aktivnosti na vježbama prevođenja jednostavno nema dovoljno vremena. Ovisno o tome koje kolegije vodi na sveučilištu, lektor može korelirati nastavu jezičnih vježbi i vježbi prevođenja. U tom slučaju sati jezičnih vježbi mogu se posvetiti razvijanju jezičnih komunikacijskih kompetencija studenata i trostrukoj analizi različitih tema, a na vježbama prevođenja moguće je prevoditi tekstove u skladu s temama jezičnih vježbi.

Budući da to nije uvijek moguće te da su studenti i voditelji vježbi svjesni tog problema, na Odsjeku za slavistiku Fakulteta za poljsku i klasičnu filologiju u Poznanju nedavno je organizirana neslužbena skupina prevoditelja, sastavljena od svih lektora i zainteresiranih studenata. Cilj je grupe sastajati se jednom mjesečno i zajedno komentirati samostalne prijevode svakog člana te s vremenom objaviti najuspjelije prijevode te tako pomoći budućim prevoditeljima $u$ afirmiranju.

\section{LITERATURA}

Fernández Guerra, A. (2012) Translating culture: problems, strategies and practical realities. Art and Subversion 3 (1) - LT.1. https://hrcak.srce.hr/116870 (19. 2. 2019.).

Gulešić Machata, M. i Grgić, A. (ur.) (2015) Hrvatski B2: Opisni okvir referentne razine B2. Zagreb: FF press.

Ivir, V. (2002) Translation of Culture and Culture of Translation. Studia Romanica et Anglica Zagrabiensia: Revue publiée par les Sections romane, italienne et anglaise de la Faculté des Lettres de l'Université de Zagreb 47-48, 117-126. https://hrcak.srce.hr/21000 (9. 12. 2018.).

Ivir, V. (1978) Teorija i tehnika prevođenja. Sremski Karlovci: Centar „Karlovačka gimnazja”.

Janikowski, P. (2012) Dydaktyka tłumaczenia ustnego a postrzeganie zadań tłumacza. U Ganczar, M. i Wilczek, P. (ur.) Rola tłumacza i przekładu w epoce wielokulturowości i globalizacji. Katowice: Śląnsk.

Kozłowska, Z. (2000) Nauczanie tłumaczenia pisemnego na język obcy a nauczanie tłumaczenia pisemnego na język ojczysty. U Setkowicz, A. (ur.) O nauczaniu przekładu. Warszawa: Wydawnictwo Tepis, 62-70.

Maljković, Z. (ur.) (2014) Pliva patka: Pjesme i brojalice za najmlađe. Zagreb: Mozaik knjiga.

Modrzejewska, K. (2000) Kompetencja kulturowa tłumacza. U Setkowicz, A. (ur.) O nauczaniu przekładu. Warszawa: Wydawnictwo Tepis, 27-34.

Nida, E. A. (1981) Zasady przekładu na przykładzie tłumaczenia „Biblii”. U Pamiętnik Literacki 72/1. http://bazhum.muzhp.pl/media//files/Pamietnik_Literacki_czasopismo_kwartalne_poswiecone_historii_i_krytyce_literatury_polskiej/Pamietnik_Literacki_czasopismo_kwartalne_poswiecone_historii_i_krytyce_literatury_polskiej-r1981-t72-n1.pdf (1. 12. 2019.).

Novosel, B. (2012) Prevođenje elemenata kulture s engleskoga na hrvatski jezik. Doktorski rad. Rijeka: Filozofski fakultet u Rijeci.

Pieńkos, J. (2003) Podstawy przekładoznawstwa od teorii do praktyki. Kraków: Kantor Wydawniczy Zakamycze.

Piotrowska, M. (2007) Proces decyzyjny ttumacza: Podstawy metodologii nauczania przekładu pisemnego. Kraków: Wydawnictwo Naukowe Akademii Pedagogicznej.

Pisarska, A. i Tomaszkiewicz, T. (1996) Współczesne tendencje przekładoznawcze. Poznań: Wydawnictwo Naukowe UAM.

Skorek, E. M. (ur.) (2006) Rysowane wierszyki. Kraków: Oficyna Widawnicza „Impuls“.

Tokarz, B. (2008) Bariery kulturowe w przekładzie. U Fast, P., Janikowski, P. i Olszta, A. (ur.) Od- 
mienność kulturowa w przekładzie. Katowice, Częstochowa: Śląsk, Wydawnictwo Wyższej Szkoły Lingwistycznej, 7-23.

Wilczek, P. (2008) Różnice kulturowe jako wyzwanie dla tłumacza. U Fast, P., Janikowski, P. i Olszta, A. (ur.) Odmienność kulturowa w przekładzie. Katowice, Częstochowa: Śląsk, Wydawnictwo Wyższej Szkoły Lingwistycznej, 25-37.

Zaręba, L. (2000) Kilka refleksji na temat kompetencji tłumacza. U Setkowicz, A. (ur.) O nauczaniu przektadu. Warszawa: Wydawnictwo Tepis, 17-26.

Vijeće Europe (2005) Zajednički europski referentni okvir za jezike: učenje, poučavanje, vrednovanje. Zagreb: Školska knjiga.

\section{TRANSLATION WORKSHOPS FOR FOREIGN STUDENTS OF CROATIAN PHILOLOGY}

The paper deals with some theoretical grounds of translation and methodology of translation teaching. The Translation Workshop course conducted at the Adam Mickiewicz University in Poznan is also presented. The main aim of the course is to inform students about theories of translation and the functional styles of the Croatian language. An additional aim is to translate as many different texts as possible from Croatian into Polish and vice versa in order to gain experience and, consequently, self-confidence in translation. The course syllabus includes an introduction to translation theories and comparison of previously translated texts by Croatian authors into the Polish language (and vice versa) with the source texts. In this way students get acquainted with the most usual pitfalls and mistakes in translation, but also with possible ways of avoiding them. The first texts that students translate individually are usually short and simple newspaper articles in Croatian, followed by translation of similar texts from Polish into Croatian. Gradually, more complicated texts are included: fiction, research articles, various kinds of forms and documents, including legal acts, regulations and certificates. The last and the most demanding phase includes the translation of poetry.

Keywords: communication competence, intercultural competence, translation competencies, translation 